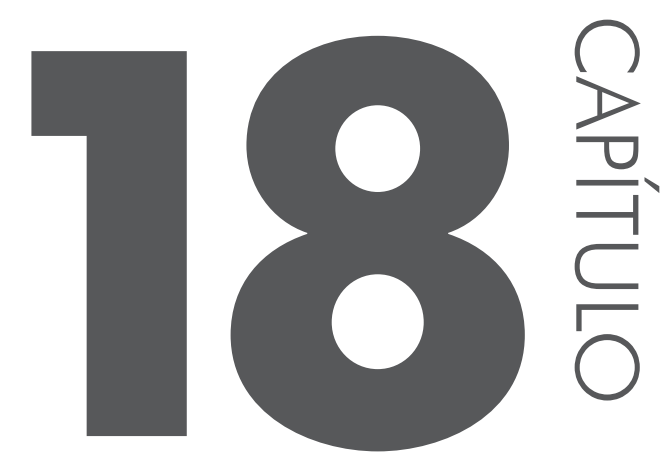

\title{
A linguística como matriz colonial: a questão das práticas orais afro-brasileiras
}

\section{Nathalia Müller Camozzato}

Mestranda do Programa de Pós-Graduação em Linguística/UFSC

\section{Introdução}

O presente trabalho, ancorado nas noções de opção descolonial (ou decolonial) (MIGNOLO, 2008; QUIJANO, 2005), resistência epistêmica (MIGNOLO, 2008) e de vontade de saber e vontade de poder (FOUCAULT, 1999), visa a investigar a matriz colonial existente na produção de conhecimentos linguísticos e metalinguísticos que culminam na assunção de certas teorias linguísticas que vigoram no formato disciplinar contemporâneo da área da linguística, ou seja, atenta-se para a formação discursiva do encontro colonial presente na suposta metodologia científica (MUDIMBE, 2013). O segundo objetivo ora adotado é demonstrar a existência de algo denominamos "ensurdecimento" dessas vertentes da linguística às questões da materialidade sonora da linguagem e suas implicações. Com isso, interpelamos os estudos da voz, da oralidade e os estudos musicológicos como maneiras de colocar em questão algumas verdades assumidas pelo campo de estudos das línguas/da linguagem. Buscamos, então, problematizar uma certa "lógica cartesiana do escrito" (DIAGNE, 2012) que rege a tradição acadêmica especialmente no interior de algumas teorias linguísticas, voltadas, por sua vez, majoritariamente, para o texto enquanto escritura e não como oralidade, musicalidade ou como performance - uma vez que mesmo quando a análise 
volta-se para os chamados "dados de fala", o faz sempre na via de transcrições, ou seja, sempre em uma relação fonema-grafema.

Para elucidar tais reflexões, consideraremos a oralidade e a musicalidade das práticas linguísticas, discursivas e culturais caracterizadas como afro-brasileiras..$^{93}$ Assume-se que tais práticas interpelam de forma particular o âmbito da oralidade e da musicalidade (MARTINS, 2003; CASTRO, 2005; 2012). Defendemos que, para investigarmos a potência e a resistência da diversidade discursiva, linguística e musical afro-brasileira no quadro pós-colonial nacional, é necessário suplantar determinadas concepções de língua sistemáticas, abstratas, reificadas, escritas e fixadas a um território - circunscritas ao limite da nação (GILROY, 1993) - conforme postulado pela linguística moderna, especialmente aquela calcada em uma perspectiva estruturalista e descritivista de língua. Trata-se de conceber a linguagem como prática social, privilegiando seus aspectos discursivos e culturais. Para nos referirmos ao universo afro-brasileiro, mobilizamos a noção de africanias (CASTRO, 2012), rompendo com um fundamentalismo teórico político que cinde, de um lado, as epistemologias europeias e, de outro, as tradições africanas. Sobre as africanias, tem-se:

[...] a bagagem cultural submergida no inconsciente iconográfico nos negrafricanos entrados no Brasil em escravidão que se faz perceptível na língua, na música, na dança, na religião, no modo de ser e de ver o mundo e, no decorrer dos séculos, como forma de resistência e continuidade na opressão, transformaram-se e converteram-se em matrizes partícipes da construção de um novo sistema cultural e linguístico que nos identifica como brasileiros. (CASTRO, 2012, p. 15).

Entendemos a importância de perceber - à luz das políticas linguísticas a dimensão da oralidade e musicalidade de práticas caracterizadas como afro-brasileiras, vista, como alertado por Queiroz (2002), a precariedade de estudos linguísticos que se ocupem de temática. Assim, pensamos, na esteira da revisão bibliográfica que Queiroz (2002) apresenta, ser premente superar os estudos - tanto no campo linguístico como no antropológico ou histórico - que buscam apenas

93 Ainda que utilizemos a designação "afro-brasileiros”, o fazemos tendo em vista a problematização de "afro hifenizados", o que, para Stuart Hall e para Paul Gilroy, é uma exclusão dos negros da história da nações. As implicações políticas de se utilizar a noção de "afro-brasileiros" é que, no Brasil, um lugar exclusivo-inclusivo é dado a esses sujeitos. Contudo, sendo a própria nação uma categoria questionável - entre diversas categorias que acabam sendo empregadas neste trabalho - o que tentamos, aqui, é mover-nos entre elas para explicitarmos questões específicas - da oralidade e da musicalidade e do seu papel no contexto afro-brasileiro - entendendo os limites deste trabalho diante da série de complexificações e problematizações que se fazem necessárias quando abordadas tais temáticas. 
a "influência" negrafricana no Brasil, como se tal brasilidade se desse aprioristicamente, e os negrafricanos trazidos em regime de escravidão para o Brasil the fossem uma exterioridade.

Sobre a oralidade, observamos aqui um tensionamento: se atualmente não podemos pensar em uma oralidade primária (ONG, 2005 [1982]), ou seja, na oralidade das referidas práticas discursivas como única materialidade para realização de tais discursos (antes sendo o caso de uma continuidade entre as modalidades oral e escrita, ou, no mínimo, coexistência), ${ }^{94}$ também as práticas orais e a cultura oral praticadas por indígenas brasileiros, africanos ou afro-diaspóricos foram, historicamente, o mote para a colonial caracterização de tais sociedades como campos simbólicos menos abstratos e mais contingentes e místicos - inferiores ao pensamento científico - primitivizando-as e tomando-as como menores cognitivamente (MARCUSCHI, 2008). Outra perspectiva que deve ser problematizada é aquela que romantiza a cultura oral, tomando-a como paradisíaca ou "filha da natureza" (FINNEGAN, 2008), obliterando as suas especificidades culturais.Por outro lado, no interior das investigações que abordam as complexas relações entre escrita e oralidade, encontramos algumas problematizações que trazem à tona questões próprias à oralidade. Podemos citar, primeiramente, Olson (2006), que questionou a atribuição de uma suposta maior complexidade e cristalização de sentidos para modalidade escrita, propondo que a escrita, ao atravessar diferentes tempos e espaços, é um terreno de equivocidades que demandam constantes exegeses, diferentemente da oralidade, que tende a desambiguizar os sentidos pelo seu contexto de produção, uma vez que

no discurso oral, um conjunto complexo de procedimentos é executado para produzir uma compreensão comum. Essas incluem não apenas a estrutura linguística e elementos prosódicos como acentos e entonações, mas também propriedades paralinguísticas, incluindo o contexto físico, conhecimento prévio compartilhado e identidade dos participantes. ${ }^{95}$ (OLSON, 2006, p. 138, tradução nossa).

94 “Oralidade e escrita são práticas com características próprias, mas não são suficientes para caracterizar dois sistemas linguísticos, nem uma dicotomia.” (MARCUSCHI, 2008, p. 17). Marcuschi traça uma distinção importante entre oralidade e letramento e fala e escrita, visto que, o primeiro par refere-se a práticas sociais e o segundo as especificidades dos registros escritos e orais. Portanto, para o autor só é cabível discernir claramente as particularidades da fala e da escrita enquanto códigos, porque, enquanto práticas sociais, ambas se interpenetram.

95 Original: "In oral discourse a complex set of procedures are play for producing a common understanding. These include not only linguistic structure and prosodic features such as stress and entonation but also paraliguistic properties including the physical context, shared background knowledge, and identity of participants." 
Já Diagne (2012), ao refletir sobre as civilizações africanas enquanto civilizações da oralidade, ou seja, civilizações que transmitem seus saberes tradicionais por meio das especificidades de práticas orais, interroga qual seria a "lógica do oral", o que lhe seria específico e o que a diferenciaria da "lógica escritutária" - na qual são transmitidos os saberes que chama de modernos. Em questão, tem-se a forma como a oralidade constitui a memória da comunidade, rompendo com a fronteira espaço-temporal. O autor menciona, ainda, que na oralidade está presente "o recurso às imagens e às metáforas e a encenação sob forma de uma história que, a seu termo, traz um ensinamento a reter" (DIAGNE, 2012, p. 332). A essas características, o autor chama de "astúcia da história oral”, ou seja, a particularidade da lógica da iniciação ${ }^{96}$ que, na história oral, constitui a forma de seleção do que é memorável - como, nesse contexto, são selecionados os saberes que deverão integrar o arquivo da comunidade, aquilo que é eleito como o que deve ser perpetuado.Vistas algumas particularidades da oralidade em relação à escrita, para pensarmos práticas linguístico-discursivas marginalizadas por um conceito de língua stricto sensu operado por determinadas vertentes da linguística, torna-se imperativo problematizar as implicações dos processos de discursivização e produção de conhecimento sobre as línguas no interior desse campo. Tem-se em questão o fenômeno que Auroux (2015) denomina gramatização. As gramatizações são processos de descrição e instrumentação das línguas, então orais, que passam a dispor de uma escrita que lhe é atribuída desde um ponto de vista eurocêntrico, processo baseado nas gramáticas e nos dicionários, os quais, por sua vez, são produzidos a partir das chaves interpretativas greco-romanas tomadas a partir da relação entre fonema-grafema ou, em outros termos, entre som e letra.

Nesse processo, as línguas gramatizadas e transformadas em escrita são lidas segundo um script completamente parcial que as isola de suas dinâmicas enquanto práticas culturais, sociais e comunicativas, criando uma rede de comunicação centrada na Europa (AUROX, 2015). Assim, não só devemos entender língua como uso e prática social, mas devemos, também, atentar para a metalinguagem que define a "língua" como um construto social, produto de intervenções culturais, sociais e históricas (MAKONI; MEINHOF, 2006, p. 194). Sobre a relação política entre oralidade e escrita em África, Makoni e Meinhof (2006) problematizam alguns fatores das políticas de letramento nesse continente, mostrando que seu impacto foi o de um "retalhamento" das formas orais de língua - isso é, a redução de línguas à sua forma escrita.

96 "Releva-se o primeiro nível, ao qual cada um pode aceder, os provérbios, os ditados, os contos e mesmo, num certo sentido, a história. O próprio núcleo central mais profundo é constituído pelo saber iniciático que, ele próprio, comporta graus” (DIAGNE, 2012, p. 334). 
Alegamos que, no aparato colonial, os estudos sobre a linguagem e as questões linguísticas desempenharam um papel decisivo de "controle, dominação, subjugação e subversão" (SEVERO; MAKONI, 2015, p. 18). As políticas de gramatização e letramento construíram relações e conflitos e instituíram conceitos de língua nos contextos pós-coloniais, privilegiando determinadas práticas linguístico-discursivas em detrimento de outras. Buscamos observar, aqui, a priorização das práticas de escrita na construção de uma concepção colonial e colonizatória de língua, em detrimento de práticas orais. Errington (2014) afirma que, nessa colonialidade da linguística, complexas situações de linguagem são reduzidas a representações escritas unívocas, fato que apresenta implicações ideológicas (ERRINGTON, 2014, p. 20).

Nesse contexto, ao mobilizarmos a opção descolonial (MIGNOLO, 2008) para pensarmos as línguas, estamos referindo a um posicionamento crítico que alia a resistência epistêmica à crítica aos padrões logocêntricos de racionalidade que subsidiaram a colonialidade do pensamento (do poder), instituindo o que é conhecer, bem como os métodos legítimos de fazê-lo. No âmbito da linguística, a adoção da opção descolonial demanda, especialmente, uma problematização do conceito de língua empregado pelo campo, privilegiadamente em relação aos fins políticos de tal conceito.

Dialogamos, com isso, com as pesquisas da linguística colonial (AUROX, 2015; MAKONI; MEINHOF, 2006; SEVERO; MAKONI, 2015; MARIANI, 2004; RAJAGOPALAN, 2013; ERRINGTON, 2014), que abordam os processos de produção de epistemologias da linguística em suas dimensões éticas, políticas e históricas. Considera-se, por um lado, as diversas influências que o contexto colonial exerceu na consolidação do campo dos estudos linguísticos (ou seja, as memórias coloniais existentes nas discursivizações sobre as línguas) e, por outro lado, o papel exercido pelos estudos linguísticos no contexto colonial, quando, por exemplo, língua e nação enlaçavam-se em um único projeto de colonização imposto pela força e pela escrita (MARIANI, 2004).

Neste capítulo, buscamos problematizar como o projeto colonial, ao apropriar-se da oralidade, da vocalidade e da em função de grafemas e da escrita (ou seja, assumindo que conhecer se dá necessariamente na esfera da visão), abordou apenas parcialmente concepções de línguas nos quais tal materialidade sonora torna-se constitutiva e veiculadora de diferentes sentidos. Defendemos que essa linguística colonialmente construída apagou de seu escopo de conhecimento um certo domínio da voz e do corpo importante e necessariamente imbricado em práticas sociais, linguístico-discursivas e performativas, como as do contexto afro-brasileiro.

A parca ressonância na linguística de discurso que assume como pedra de toque questões que digam respeito às práticas linguístico-discursivas orais parece 
deflagrar uma certa concepção que toma o caráter oral de determinadas práticas de algumas culturas apenas sob o signo da ausência da tecnologia da escrita, sem considerar as particularidades da oralidade (MARCUSCHI, 2008; MAKONI; MEINHOF, 2006; ERRINGTON, 2014). É preciso que tomemos a tradição oral como uma especificidade, uma visão de mundo, e não apenas como ausência de uma determinada tecnologia. É preciso, ainda, que suplantemos a noção de tradição como contraponto à modernidade (DIAGNE, 2012). A voz e a oralidade produzem sentidos outros que precisamos aprender a ouvir, uma vez que também incidem nos discursos e nas interações dadas nessa modalidade.

\section{Os estudos linguísticos e a escrita: o olhar fundador do objeto}

Admite-se, neste trabalho, que a frequente elisão das questões pertinentes à oralidade na sua relação com as africanias no campo de estudos da linguística seja pela sua submissão ao letramento, seja pela sua análise estrutural e descritiva - ressoa uma dada memória colonial que conserva relações de poder específicas. Severo e Makoni (2015), por exemplo, destacam que, na linguística colonial (especificamente na lusitanização), a Igreja Católica foi agente determinante de produção de conhecimentos linguísticos sobre as línguas ditas "exóticas". ${ }^{97}$ Sabe-se que o texto, no caso do cristianismo, apresenta a autoridade de escritura sagrada que fixa e perpetua sentidos (CAVAREIRO, 2011; OLSON, 2006). Diante dessa textualidade, portanto, a oralidade e a vocalidade são tomadas como excessivamente corpóreas e contingentes. Conforme Errington, "linguística colonial precisa ser concebida aqui como uma relação de tecnologia (literacia), razão e fé, e como um projeto de múltipla conversão: de pagão para cristão, de fala para escrita e de alienígena para compreensível"98 (ERRINGTON, 2014, p. 21, tradução nossa).No que tange à história política das ideias, Caraveiro (2011) associa à perpetuação do logocentrismo metafísico uma perspectiva videocêntrica, caracterizada pelo predomínio da esfera da visão na construção ocidental de conhecimentos legitimados pelo seu valor de verdade. Entende-se que uma concepção de língua

97 Leda Maria Martins, convenientemente, nos fala de ex-óticos como aquilo que, ao escapar à metáfora do ver como conhecer, é exotizado e tomado como exterior à esfera daquilo que se deve conhecer. A autora ressalta, também, o papel da escrita nesse processo: "Nessa ordem, o domínio da escrita torna-se metáfora de uma ideia quase exclusiva da natureza do conhecimento, centrada no alçamento da visão, impressa no campo ótico pela percepção da letra”. (MARTINS, 2003, p. 64)

98 Do original: "Colonial Linguistics needs to be framed here, then, as a nexus of technology (literacy), reason and faith, and as a Project of multiple conversion: of pagan to Chrstian, of speech to writing, ando f the alien to the comprehensible" (ERRINGTON, 2014, p. 21). 
videocêntrica caracteriza a língua enquanto escrita (sua visualidade), ou enquanto abstração (seja enquanto conceitos puros ou como reflexos do pensamento, característica de vertentes mais cognitivistas).

Filósofos contemporâneos como Jean-Luc Nancy (2011) e Mladem Dolar (2007) têm questionado o predomínio do espectro da visão como um sentido "sensato", ou seja, capaz de nortear reflexões cartesianas, em oposição e em detrimento da audição, um sentido sensível, logo, "falho" e "enganoso". Cavareiro (2011) nos chama atenção para o fato de que, uma vez que se está mobilizando sentidos sensíveis, operar com a voz demanda um retorno ao corpo, na busca de sentidos outros que não sejam sentidos lógicos.

Foucault, em O Nascimento da Clínica (1977), abordou o poder exercido pelo sentido da visão na conversão da linguagem em discurso racional, quando a precisão do olhar passa a penetrar a opacidade dos corpos, e isso lhe confere valor de verdade: o olhar como o fundador do objeto visto (FOUCAULT, 1977). No caso da linguística, temos como exemplo a abordagem estruturalista de Saussure, que, na tentativa de produzir uma linguística que superasse a "tirania da escrita" (SAUSSURE, p. 40), acabou por tomar os sons da linguagem apenas enquanto "imagens acústicas". Esse conceito se vincula ao regime de verdade da visão, pois está calcado na relação entre fonemas e grafemas.

No regime de verdade do ver como conhecer, encontra-se, por exemplo, a etimologia de termos como aletheia, cujo sentido de verdade é literalmente dado por "aquilo que não está escondido", ou theoria, do verbo theoren, que significa "contemplar"; tem-se, ainda, o termo latino scientia, que designa "um avistamento que ocorre quando se está tentando ver" (CAVAREIRO, 2011). A constituição da linguística enquanto campo está necessariamente vinculada à sua afirmação enquanto ciência, ou seja, impregnada de uma prerrogativa que Cavareiro (2011) denomina videocêntrica.

Essa constituição científica da linguística em seu formato estruturalista Saussure (1916) afirma estar esclarecendo os limites da linguística em relação às outras ciências, por meio de uma definição clara do que constitui seu objeto - é abordada por Bordieu em Economia das trocas linguísticas" (1996), no qual o autor entende que o campo passa a trabalhar a língua/a linguagem como uma finalidade sem fim que confere "[...] os encantos de um jogo formal e inconsequente aos exercícios puros de uma análise puramente externa e formal” (BORDIEU, 1996, p. 19). Nesse jogo estrutural, “[...] a descrição científica mais constatativa sempre corre o risco de funcionar como uma prescrição capaz de contribuir para sua própria verificação" (BORDIEU, 1996, p. 123).

Vinculando a linguística com contextos africanos, Fardon e Furniss (1994) alertam que os "problemas linguísticos" encontrados pela realização de políticas 
linguísticas em África são criados justamente pelo prisma linguístico eurocêntrico que entende línguas a partir de um dado regime de produção e legitimação de verdade. Os problemas de que falam os autores dizem respeito à errônea noção de que, peremptoriamente, as línguas e os discursos devem enquadrar-se às chaves interpretativas dadas a priori, e não o contrário. Nessas descrições/prescrições/ criações de línguas segundo determinadas interpretações, as diferentes implicações assumidas pela oralidade eram eclipsadas, mesmo tratando-se de contextos chamados de "oralidades primárias" (ZUMTHOR, 1990; ONG, 2005[1992]), ou seja, de línguas que não apresentavam a forma escrita. Aliás, a próprio uso do termo "primário" remete para uma hierarquização das formas de expressão.

Podemos estender esse fenômeno diagnosticado por Fardon e Furniss (1994) aos limites da linguística em relação à apreensão da complexidade das práticas linguístico-discursivas perpassadas pela tradição oral, como aquelas vinculadas à matriz cultural e religiosa afro-brasileira. Tais práticas têm sido analisadas, unicamente, em uma chave descritiva e estruturalista, reforçando a relação fonema-grafema problematizada antes. Rodrigues (1933), em sua controversa obra, ${ }^{99}$ coincidentemente, também denomina de "problemas linguísticos" a impossibilidade de se rastrear com precisão os troncos linguísticos das línguas africanas que encontrou no Brasil, dada a fragmentação e interpenetração entre tais línguas no contexto pós-colonial - e ainda, em diálogo com Fardon e Furniss, Rodrigues parece assumir a definição de que uma "língua" é dada a priori, definida enquanto unidade e não como as práticas linguísticas com as quais se deparou.No contexto atual afro-brasileiro, verifica-se, por um lado, a existência de certa contiguidade entre a oralidade e o letramento, no qual as práticas litúrgicas afro-brasileiras possuem suas diferentes discursividades - mitologias, cânticos, pontos cruzados e pontos riscados, entre outras semioses - editadas em diferentes meios escritos (PRANDI, 2014; CANTIGAS, 2011). Por outro lado, na dinâmica ritual, cultural e social, e, ainda, na perpetuação de tais discursividades, a oralidade e a musicalidade exerceram papéis fundamentais, seja na esfera religiosa, seja na esfera da musicalidade (CASTRO, 2005; 2012).

Propomos pensar as práticas orais que caracterizam a afro-brasilidade como rastros-resíduos, ${ }^{100}$ conceito cunhado por Glissant (2005) para refletir sobre a

99 Nina Rodrigues é assumido como primeiro autor a produzir um trabalho sociológico sobre os negros no Brasil. Contudo, sua obra é permeada pelas teorias antropológicas evolucionistas então vigentes na época e inadmissíveis nos dias atuais (QUEIROZ, 2002).

100 "Contra as reviravoltas dessas velhas estradas já trilhadas, o rastro-resíduo é a manifestação fremente do sempre novo. Porque o que ele entreabre não é terra virgem, a floresta virgem, essa paixão feroz dos descobridores. Na verdade o rastro-resíduo não contribuiu para completar a totalidade, mas permite-nos perceber o indizível em sua totalidade. O sempre novo não é mais o que falta descobrir para completar a totalidade, o que falta descobrir nos espaços brancos 
crioulização linguística e cultural antilhana. Acreditamos que para tais rastros-resíduos, estilhaços da fratura da diáspora negro-africana, caberia uma análise que contemple sua potência de desestabilizar as normatizações escritas - Glissant caracteriza a escrita como a modalidade nas quais são produzidas as narrativas atávicas: mitos que se tornam História (escrita com $\mathrm{H}$ maiúsculo) após um épico originário e legítimo. Rastros-resíduos são contemplados em seu potencial relacional de criação e crioulização polivalente da escrita e da norma, sem, contudo, produzir síntese. Nesse sentido, pensando em línguas africanas no contexto afro-brasileiro, a tentativa de recompor sua totalidade estrutural enquanto unidade linguística não comporta a sua potencialidade discursiva (veja-se o exemplo de Nina Rodrigues, citado acima). A oralidade é mais do que representações linguísticas codificadas. Trata-se de uma esfera simbólica privilegiada, na medida em que estabelece novas e imprevisíveis relações na dinâmica do "caos-mundo" - noção empregada por Glissant (2005) para representar a imprevisibilidade de relações possíveis no âmbito da oralidade e da crioulidade. Defendemos que a construção de interpretações que tomam a língua e os discursos como objeto no interior de uma matriz videocêntrica (CAVAREIRO, 2011) silencia toda uma rede de performances, de experiências, de memórias e, especialmente, de discursividades e práticas culturais e sociais. Apaga-se, com isso, o papel da linguagem como espaço de práticas políticas. Nesse sentido, silenciar a materialidade sonora da linguagem em função de uma perspectiva videocêntrica e logocêntrica pode também ser visto como uma estratégia política colonial.

Dessa forma, problematizada a esfera que denominamos videocêntrica (CAVAREIRO, 2011) no interior de determinadas práticas da linguística - ou seja, a redução das práticas linguístico-discursivas à escrita - propomos que, para contemplar a complexidade da oralidade, seja necessária uma abordagem interdisciplinar em diálogo com as contribuições de outras áreas de conhecimento, como a literatura, a antropologia, a musicologia e a história, entendendo que o fenômeno da oralidade, em sua complexidade, exige a integração de distintas formas de análise e interpretação.

\section{Linguística, estruturalismo e silenciamento}

Esta seção busca problematizar o silenciamento conferido à oralidade na obra seminal da linguística moderna, Curso de linguística geral (2006[1916]), de Ferdinand de Saussure. Trata-se de considerar esse silenciamento como um gesto político colonial que afeta as práticas discursivas orais ao submetê-las a uma

do mapa, mas aquilo que nos falta ainda fragilizar para disseminar, verdadeiramente, a totalidade, ou seja, realizá-la totalmente” (GLISSANT, 2001, p. 71). 
dada representação. Nesse sentido, é cabível refletir sobre a obra de Ferdinand de Saussure como subsidiária dos fazeres coloniais e políticos implicados em a uma dada representação de língua calcada na abstração. Um caso exemplar do nível abstrato com que a materialidade sonora é tomada é, como já mencionado, sua caracterização em Saussure (2006/1916) enquanto “imagem acústica”.

É necessário que sempre tenhamos em mente que a representação de língua como estrutura, ainda que tomada apenas como um fenômeno descritivo e caracterizado por uma suposta neutralidade científica, serve a políticas de língua universalizantes e estruturantes que submetem as manifestações linguísticas pela prática da categorização (BORDIEU, 1996). A categorização de língua, contudo, nunca é neutra, mas politicamente caracterizada (RAJAGOPALAN, 2003).

A despeito de o Curso de linguística geral ter sido reiteradamente apontado como uma obra fonocêntrica (DERRIDA, 1973), entendemos que tal fonocentrismo deva ser modalizado, uma vez que a fala observada por Saussure é uma fala virtual, anônima. A fonética moderna, depositária dos conhecimentos produzidos pelo estruturalismo, detém-se no fonema a serviço dos grafemas, ou seja, toma-o por uma entidade relativa, uma vez que considera os fonemas enquanto diferenças produtoras de contrastes que permitem distinguir entidades lexicais, relegando ao plano paralinguístico as diferentes timbrações e prosódias, as variações de altura, intensidade, e duração dos sons, ou seja, os fenômenos fônicos que geram contornos melódicos (RAPOSO, 2006 apud TRAVASSOS, 2008). Assim, de forma ambivalente, apesar da hipótese do fonocentrismo, verifica-se, paradoxalmente, a eliminação do fator oralidade/vocalidade desse aparato metodológico, fenômeno coerente com o silenciamento que entendemos como concernente à esfera da colonialidade que atravessa o campo da linguística

Assim, os sons linguísticos percebidos pela chave estruturalista parecem cheios de uma intencionalidade intrínseca, como se um som tivesse, por si, a vontade de dizer algo. Essa interpretação implica a concepção da voz apenas como instrumento de significado semântico, noção criticada por Dolar (2011). O que Dolar, em sua crítica à linguística da voz recomenda é a busca de aproximações que não tomem a voz nem por excesso (ou resto) da linguagem, nem como apenas meio no qual se realizam os sentidos semânticos.

Finalmente, na linguística estruturalista, o que aqui se coloca em xeque é sobretudo a forma de codificação dos sons da linguagem - interpretados pelas áreas da fonética e da fonologia. Em sua fundamental distinção entre langue e parole e, ao assumir que é no nível do sistema da langue (isso é, da abstração), que a atenção do pesquisador da linguagem deve se ater, o estruturalismo linguístico postula que se deva ignorar a concretude da fala (parole), justamente o lugar onde os elementos da voz e da oralidade se realizam e ressoam. O exemplo desse apagamento pode ser dado na seguinte asserção, encontrada na obra fundamental 
de Saussure: "o som não passa de um instrumento do pensamento e não existe por si mesmo" (SAUSSURE, 2006, p. 16). Nessa chave de compreensão, portanto, os sons da língua não passam de acessório e acidental. Dessa forma, se somos levados a crer, por diversas razões, que mesmo diante do fato de que a linguística assume ter por objeto a fala, e não a escrita, ela não constitui, contudo, um terreno que propicie refletir sobre a oralidade enquanto evento discursivo, uma vez que se trata apenas dos "sons da fala", sons reificados, abstratos que não parecem emergir de nenhum falante ou de nenhuma corporeidade.

Ao nos situarmos no interior de uma opção descolonial, para além de problematizarmos a leitura de Saussure sobre os sons da fala, devemos também questionar seu postulado de que "[...] o linguista deve buscar forças permanentes e universais das quais deve deduzir leis gerais que para os fenômenos da história das línguas" (SASSURE, 2006[1916], p. 13). Evidentemente, isso diz respeito à construção universalizante de uma ciência calcada nas noções de uno, de total, de verdadeiro.

Lançar-se sobre a linguagem implica dirigir-se a um campo marcado pela complexidade e pela heterogeneidade. A opção descolonial, enquanto crítica de pensamentos colonizadores que, embora tomados por universais, são particulares (MBEMBE, 2014) - o que também quer dizer que historicamente situados e politicamente motivados -, nos oferece meios de questionar esse aspecto da linguística. Butler (1998) afirma que a categoria imposta sob o signo do "universal" é um lugar de disputa política permanente, e que os fundamentos das teorias - aqui os fundamentos de uma determinada linguística - funcionam como o "inquestionável" dessas mesmas teorias, suas bases autorizantes. Dessa forma, questiona a autora: "Como poderemos fundamentar uma teoria ou política numa situação de discurso ou posição de sujeito que é 'universal' quando a própria categoria do universal apenas começa a ser desmascarada por seu viés altamente etnocêntrico?” (BUTLER, 1998, p. 16-17).

Esta seção teve por objetivo evidenciar como as concepções estruturalista de linguagem praticadas no interior de algumas frentes da linguística não oferecem uma interpretação suficiente para contemplar a dinâmica de práticas linguístico-discursivas perpassadas pela oralidade. Assim, na próxima seção, buscamos ilustrar a maneira como a matriz colonial influenciou os estudos linguísticos ocultou aspectos importantes das práticas linguístico-discursivas de alguns sujeitos e de línguas. 


\section{Práticas linguístico-discursivas afro-brasileiras}

Nesta seção, desejamos apontar caminhos teóricos que se alinham à noção de resistência epistêmica, os quais discutem, particularmente, as práticas linguísticas e discursivas caracterizadas como musicais e como da cultura afro-brasileira ou ainda afro-hifenizada nas Américas.

Em termos da musicalidade africana, Gilroy (1993) propõe que artes negras - e, em especial, a música - constituem dispositivos de resistência e de interpenetração nas culturas nacionais que os invisibilizava/ensurdecia. Para analisar esse aspecto, o autor propõe a noção de Atlântico Negro, como representativa de um espaço de trocas, intercâmbios e hibridismos, antítese da fixidez territorial do Estado-nação que excluiu de seu seio os negrafricanos (e suas práticas linguístico-discursivas). Para o autor, no Atlântico Negro, a perspectiva dos sujeitos afro-diaspóricos como mercadorias é substituída por uma nova, na qual os mesmos são agentes de resistência engajados em lutas sociais, discursivas, estéticas e políticas.

A musicalidade negra, para Gilroy, é o principal símbolo da autenticidade racial, sendo uma "transvalorização de todos os valores" (GILROY, 1994, p. 94), conjugando ética, estética, cultura e política. Ademais - semelhantemente à avaliação que fazemos de uma certa linguística em seu apagamento da oralidade e da vocalidade - Gilroy entende que a modernidade excluiu a música de suas análises críticas e encontra padrões distintivos do uso da língua na diáspora africana moderna e ocidental, que dizem respeito à oralidade. Assim:

\footnotetext{
Pensar sobre música - uma forma não figurativa, não conceitual - evoca aspectos de subjetividade corporificada que não são redutíveis ao cognitivo e ao ético. Essas questões também são úteis na tentativa de situar com precisão os componentes estéticos distintos na comunicação negra. (GILROY, 1994, p. 163).
}

Um exemplo do papel da musicalidade em relação às práticas discursivas afro-brasileiras remete-se aos trabalhos de Martins (2003), que opera com a cosmovisão da experiência de religiosidade afro-brasileira para criar dispositivos teóricos designados como "exu”, "encruzilhada" e "oralitura". Ao cunhar o conceito de "oralitura”, Martins (2003) nota que a memória, no caso da religiosidade afro-brasileira, não se realiza nos registros escritos ou na relação fonema-grafema, mas, sim, por meio de "um traço residual estilístico, mnemônico, culturalmente constituído, inscrito na grafia do corpo em movimento e na vocalidade" (MARTINS, 2003, p. 97). Trata-se aqui de pensar em um outro ambiente de grafia e postulação da memória, na inscrição de discursos na voz e no corpo que performatizam a oralidade e as práticas rituais. Martins, por exemplo, questiona 
o domínio da visão que caracteriza a escrita, naquilo que já denominamos como "ver para conhecer":

Nessa ordem, o domínio da escrita torna-se metáfora de uma ideia quase exclusiva da natureza do conhecimento, centrada no alçamento da visão, impressa no campo ótico pela percepção da letra. A memória, inscrita como grafia pela letra escrita, articula-se, assim, ao campo e processo da visão mapeada pelo olhar, apreendido como janela do conhecimento. Tudo que escapa, pois, à apreensão do olhar, princípio privilegiado de cognição, ou que nele não se circunscreve, nos é ex-ótico, ou seja, fora de nosso campo de percepção, distante de nossa ótica de compreensão, exilado e alijado de nossa contemplação, de nossos saberes. (MARTINS, 2007, p. 64).

Martins também explora a maneira como a voz pode ser tomada no interior dos estudos da linguagem:

No âmbito dos rituais afro-brasileiros, a palavra poética cantada e vocalizada ressoa como efeito de uma linguagem pulsional e mimética do corpo, inscrevendo o sujeito emissor, que a porta, e o receptor, a quem também circunscreve, em um determinado circuito de expressão, potência e poder. Como sopro, hálito, dicção e acontecimento performático, a palavra proferida e cantada grafa-se na performance do corpo, portal da sabedoria. Como índice de conhecimento, a palavra não se petrifica em um depósito ou arquivo estático, mas é essencialmente kinesis, movimento dinâmico, e carece de uma escuta atenciosa, pois nos remete a toda uma poieses da memória performática dos cânticos sagrados e das falas cantadas nos rituais. (MARTINS, 2007, p. 23).

Ressalta-se que as análises de Martins e de Gilroy consideram a dimensão estética das práticas orais afro-brasileiras e afro-hifenizadas, localizando essas práticas em uma dada dimensão interpretativa. Reiteramos, assim, a pertinência de diálogo da linguística com os campos que compartilham do estudo das línguas e dos discursos em diferentes dimensões (como a estética) vista a complexidade da oralidade. Zumthor (1990), por exemplo, propõe uma ciência da voz e da oralidade, que conjugue os conhecimentos das áreas da física, da fisiologia, da linguística, da antropologia e da história. Acreditamos que o diálogo interdisciplinar é válido, tendo em vista que "o movimento transdisciplinar ${ }^{101}$ [...] direciona seu interesse na ideia de processo, de diálogo e de ação em detrimento da definição de objetos de estudo enquanto produtos, estruturas, ou obras definitivas" (FINNEGAN, 2008, p. 21). O enfoque desliga-se da noção de "arte como produto" para

101 Assumimos que, embora as categorizações “interdisciplinar" e "transdisciplinar" possuam características próprias e determinantes, elas assemelham-se quanto a uma tomada de postura de diálogo e cooperação entre as disciplinas. 
observar as práticas dos sujeitos e as subjetividades em questão.Um exemplo de prática oral afro-brasileira é o caso das línguas de santo. Castro (2005) nos oferece uma definição de língua de santo que a toma como um repertório linguístico e simbólico integrado aos diversos elementos das cerimônias sagradas:

[...] compreende sistemas lexicais de antigos falares africanos no Brasil, vindo a constituir uma língua de aspecto sagrado, mas não declaradamente de natureza sobrenatural, porque se acredita tratar-se do idioma nativo da divindade, que, eventualmente, pode vir a ser identificado com uma das línguas de uma nação política africana atual. Dessa maneira, durante a cerimônia litúrgica canta-se para o vodum em jeje-mina, para o orixá em nagô-queto, para o inquice em congo-angola. Tal repertório do domínio religioso comum torna-se lenta e inconscientemente diferenciado pelos seus praticantes, pelo fato de ser habitualmente usado em cerimônias religiosas dessa ou daquela determinada "nação-de-candomblé”. (CASTRO, 2005, p. 83).

Os sentidos e a potência dessas línguas nos contextos rituais, para a autora, residem em suas formulações simbólicas, sendo que, para os envolvidos na comunidade ritual, importa menos a compreensão da denominação dos referentes (isso é, saber o significado literal da cantiga) e mais o saber sobre as regras de uso da canção em que a língua se encontra, como o momento em que ela deve ser entoada e como se dá em relação com a dinâmica ritual. Ademais, se o conhecimento estrutural das línguas, por um lado, pode engendrar posições de poder sacerdotal, por outro, ele não é requisitado dos partícipes dos rituais. ${ }^{102}$ Para ilustrar essas práticas orais, abaixo seguem três cantigas que integram o repertório discursivo-musical de diferentes vertentes de religiões de matrizes africanas. As cantigas foram selecionadas em função de figurarem uma certa tradição da música popular e apresentarem zonas de contato entre línguas africanas e o português brasileiro, caracterizando práticas híbridas. Ainda, nesse sentido, a língua hegemônica se torna também um lugar de reconstrução (APIAH, 2007). Não obstante, entendemos que a transcrição escrita, restrita ao texto das canções, não contempla sua totalidade enquanto performance, sendo, portanto, apenas indicativas das práticas que abordamos aqui (FINNEGAN, 2008).

102 Finnegan (2008) atenta para o fato de que, no caso das canções em geral, o conteúdo verbal não está necessariamente veiculando sentidos que devam ser interpretados pelos ouvintes, seja em canções sagradas, seja por meio de palavras referenciais: "tralalás”, "ba-da-uás”, "iê-iê-iês”, ou versos terminados em “oh”, “ah”, “e-iêe”. "Em muitos gêneros, é a eficácia sonora da performance aliada às grandes expectativas criadas pelo conhecimento das convenções relevantes e do repertório que moldam a experiência, mais do que o conteúdo verbal cognitivo" (FINNEGAN, 2008, p. 32). 
Tabela 18.1 - Cantigas e Pontos Cruzados de Candomblé e Umbanda.

\begin{tabular}{|c|c|c|}
\hline $\begin{array}{l}\text { Cantiga de } 0 \text { xum na } \\
\text { umbanda }\end{array}$ & $\begin{array}{l}\text { Cantiga de lemanjá no } \\
\text { candomblé }\end{array}$ & Ponto de caboclo boiadeiro \\
\hline $\begin{array}{c}\text { Eu vi mamãe Oxum na } \\
\text { cachoeira, } \\
\text { Eu vi Mamãe Oxum na } \\
\text { cachoeira, } \\
\text { Colhendo lírio, lírio, ê } \\
\text { Colhendo lírio, lírio, á, } \\
\text { Colhendo lírio pra enfeitar } \\
\text { o seu gongá (bis) }\end{array}$ & $\begin{array}{l}\text { Ferimã, Ferimã, } \\
\text { Ferimã, abaizô, } \\
\text { Olirá, Olirá, } \\
\text { Asobá abaizô. } \\
\text { Micaá, } \\
\text { Selumbanda queromindi } \\
\text { Dí mamãe ê, ê micaiá } \\
\text { selumbanda } \\
\text { Querominda de mamãe ê, } \\
\text { micaiá, ê } \\
\text { lemaniá assobá, } \\
\text { Sobá mi rerê (bis) } \\
\text { Sóba mi rerê, ó Dôla } \\
\text { Sóba mi rerê (bis) }\end{array}$ & $\begin{array}{l}\text { Eu não sou daqui, } \\
\text { Sou marinheiro só, } \\
\text { Eu sou do amor, } \\
\text { Marinheiro só } \\
\text { Eu vim da Bahia, } \\
\text { Sou marinheiro só, } \\
\text { De São Salvador, } \\
\text { Sou marinheiro só. }\end{array}$ \\
\hline
\end{tabular}

Fonte: Cantigas (2011).

As cantigas, cânticos e rituais não se circunscrevem ao âmbito das casas afro-brasileiras. A música popular brasileira, especialmente o leque abarcado pelo samba, apresenta uma relação íntima com as práticas que são caracterizadas como da religiosidade afro-brasileira. Embora essas práticas se vinculem a esferas socioideológicas diferentes, não se buscam aqui especificidades que trazem uma distinção entre ambas. Nesse sentido, Castro ([s./d.]) expõe o fato de que a língua de santo é a fonte atual dos aportes lexicais africanos no português, e que a música popular brasileira tem sido seu principal meio de divulgação.

Exemplificando a articulação entre religiosidade e música popular, a Cantiga de Oxum, presente na Tabela 17.1, já foi gravada por Mariene de Castro, Zeca Baleiro, entre outros; e o Ponto de Caboclo Boiadeiro teve versões gravadas por Marisa Monte, Caetano Veloso, Clementina de Jesus, para citar apenas alguns. É perceptível que, nesses contextos nos quais as práticas linguístico-discursivas culturais, as africanias e os sentidos de cultura popular se interpenetram, geran- 
do novos sentidos em uma zona intersemiótica que intercepta estética, religião e política, construindo sentidos que ora visibilizam, ora invisibilizam uma dada afro-brasilidade.

$\mathrm{Na}$ tabela a seguir, são apresentadas outras músicas que ilustram a afro-brasilidade na relação entre cultura popular e musicalidade. Essas canções foram selecionadas em função de integrarem diferentes quadros discursivos, em diferentes regiões do Brasil, e por sua musicalidade ser categorizada por diferentes estilos, compondo um complexo quadro musical-discursivo em que os sentidos de afro-brasilidade, música popular, oralidade e língua não são dados a priori, mas devem ser contextualizados e vistos caso a caso. As canções abaixo também apresentam diferentes gradações entre a presença de línguas africanas - interpenetradas entre si e com o português brasileiro - novamente caracterizando práticas híbridas. 
Tabela 18.2 - Canções da Música Popular Brasileira que Dialogam com as Africanias

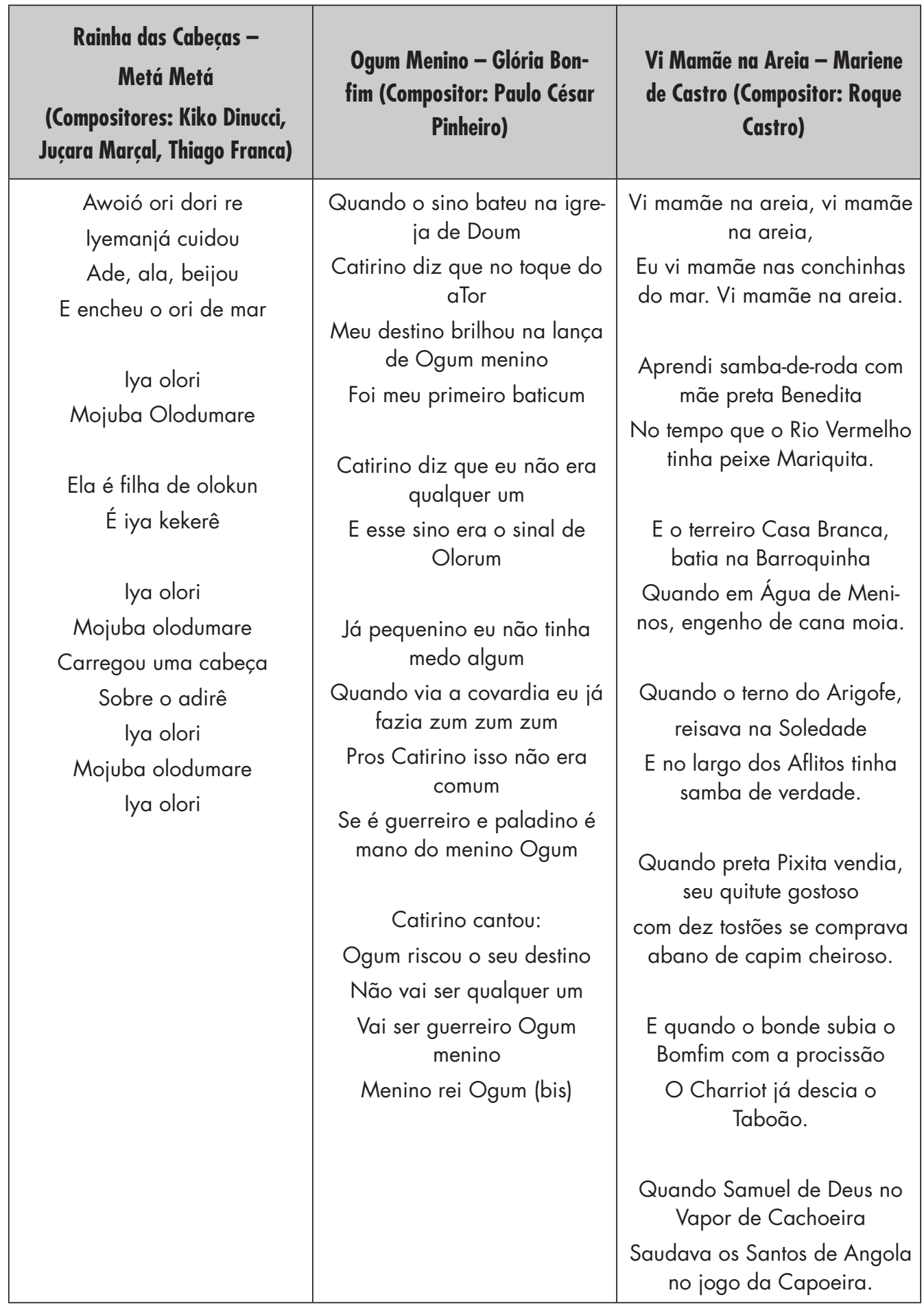


A primeira canção, Rainha das cabeças, foi composta e gravada por Metá Metá (2012), banda paulistana que se autodenomina "afro punk" e integra um circuito alternativo que se expande para públicos mais abrangentes. A canção é do segundo álbum da banda, chamado "Metal Metal". A segunda canção integra o disco de estreia - Santo e orixá (2007) - da cantora baiana Glória Bomfim, com canções de temática afro-religiosa. E a terceira canção, da cantora carioca Mariene de Castro, cantora que também dialoga com as questões de religiosidade e africanias em diálogo com a música popular brasileira.

Sobre as relações entre língua e musicalidade brasileira, é de Castro ${ }^{103}$ (2015) a afirmação de que a língua brasileira é culturamente negra, e que é na oralidade do português falado hoje no Brasil que se verifica a interpenetração das línguas bantas com a língua portuguesa. Em termos estruturais, essa incidência se verifica especialmente no que diz respeito à riqueza das vogais existente na fala brasileira, influência da ausência de grupos consonantais nas línguas do grupo bantu, exemplificada seja pela busca pela estruturação silábica no formato $\mathrm{C}+\mathrm{V}$ (consoante e vogal $)^{104}$ e no aspecto de uma prosódia “cantada", ou seja, a musicalidade atribuída geralmente à fala do português brasileiro. A autora cita, ainda, o princípio de economia que gera a concordância do plural como em "os menino", entre outras marcas da oralidade da língua que são frequentemente tomadas na perspectiva do erro, incentivando preconceitos linguísticos.Finnegan (2008) aponta que o estudo das canções pode ser revisto à luz do que a autora chamada de "paradigma da performance", no qual texto, música e performance operam em conjunto, sem hierarquias. Finnegan problematiza a análise de canções restritas ao paradigma escrito no qual “o modelo mais recorrente foi de associar o 'sentido' ao texto e o som à ‘emoção’ ou à música” (FINNEGAN, 2008, p. 18).

Fechamos essa seção trazendo as considerações de Finnegan (2008) que buscam borrar as fronteiras de oposição entre linguagem e música - problematizando-as como etnocêntricas e impraticáveis. A complexificação das oposições entre música e linguagem feita por Finnegan questiona a naturalização de ambos como conceitos em oposição, trazendo a interpenetração da música na linguagem e da linguagem na música:

103 Castro identifica nessa coexistência das línguas africanas na esfera da oralidade do português brasileiro a razão pela qual não se encontram "crioulos" no Brasil: "houve o mesmo tipo de encontro do português arcaico com essas línguas, que eram faladas majoritariamente no Brasil. Em vez de haver um choque, em vez da necessidade de emergir outro falar, um falar crioulo, não: houve simplesmente uma acomodação, devido às coincidências dessas estruturas linguísticas” (Castro, 2015).

104 Caso da inserção de uma vogal onde haveria apenas uma consoante, como em "adiquirir" para adquirir ou, ainda, do reforço como em "treis" para três. 
Em todo caso, nem "linguagem” nem "música” são conceitos unívocos ou coisas dadas, livres de ambiguidades. Cada uma engloba uma pletora de propriedades distintas e superpostas as quais não podem ser igualmente desenvolvidas - ou mesmo estar presentes - em nenhum exemplo dado. Qualquer oposição entre elas será inevitavelmente tendenciosa, ou seletiva na melhor das hipóteses, referindo-se a apenas alguns dos elementos possivelmente envolvidos. A justaposição corrente e convencional de linguagem e música evoca com frequência uma oposição bastante artificial entre as artes performáticas da música, de um lado, e a supostamente "neutra" linguagem do dia-a-dia, de outro. (FINNEGAN, 2008, p. 32).

Finalmente, esta seção buscou: (i) abordar as questões referentes à oralidade e à musicalidade para a experiência afro-brasileira e afro-americana; (ii) ilustrar as práticas linguístico-discursivas caracterizadas como afro-brasileiras com exemplos de canções atreladas à religiosidade e à música popular; e (iii) discutir as diferentes relações entre língua e oralidade/musicalidade.

\section{Conclusão}

Buscamos, ainda que de forma genérica, discutir a maneira como a matriz colonial influenciou/influencia determinados estudos linguísticos e como, nessa relação, foram elididos aspectos determinantes das práticas linguístico-discursivas. Exemplos são as questões da voz, da oralidade e da musicalidade em práticas da nomeada cultura afro-brasileira. Ademais, dentro da noção de resistência epistêmica e de opção descolonial, buscamos, aliando crítica e política, fazer uma leitura crítica de certos fazeres da linguística enquanto disciplina historicamente situada e, por outro lado, explorar outras formas de conhecer que interpelam distintos saberes e diferentes visões de mundo.

Defendemos que a abordagem da oralidade, da vocalidade ou mesmo da musicalidade requer um diálogo interdisciplinar entre a linguística, a literatura, a musicologia, a antropologia, entre outras áreas de conhecimento; e que a linguística pode se beneficiar desse diálogo. Entendemos também como importante uma aproximação à noção operada pela musicologia de "multimodalidade", na qual "o visual, o somático, o gestual, o material - tudo pode fazer parte" (FINNEGAN, 2008, p. 35). Nesse sentido, tampouco a oralidade e a musicalidade podem ser isoladas do contexto multimodal em que são performatizadas (incluindo-se vestuário, práticas, gestualidades e alimentos, no caso da religiosidade afro-brasileira), algo semelhante ao postulado por Roy Harris (1987) quando o mesmo pensa a língua segundo a noção de integracionismo.

Que tipos de reflexão surgiriam quando se toma a língua em uma perspectiva integracionista (HARRIS, 1987), pensando-a para além de uma unidade reificada, como perpassada por um sistema intersemiótico complexo? Que tipos de me- 
todologias poderiam ser empregadas e quais discussões seriam pertinentes para uma discussão que mescle ética, estética e política para abordagem das culturas orais? Essas são as questões que propomos como fundamentais para o avanço da aproximação dos estudos da linguística em relação as práticas da oralidade.

Finalmente, concluímos que a oralidade e a musicalidade caracterizadas como afro-brasileiras nos oferecem uma experiência crítica (QUIJANO, 2007) capaz de deslocar os sentidos naturalizados como universais, como aqueles que separam a língua da musicalidade (FINNEGAN, 2008) ou a língua do contexto comunicativo (HARRIS, 1987). Ademais, como Butler nos adverte, tal como a filosofia, a teoria está empenhada em exercer poder (BUTLER, 1998) e, nesse sentido, as reflexões teóricas, éticas e estéticas tornam-se reflexões políticas.

\section{Referências}

APPIAH, K. A. Na casa de meu pai. Rio de Janeiro: Contraponto, 2007.

AUROX, S. A revolução tecnológica da gramatização. Tradução de Eni Puccinelli Orlandi. 2. ed. Campinas: Unicamp, 2009.

BATISTA, R. O. Uma história dos estudos sobre a linguagem no Brasil: gramáticas coloniais, diversidade linguística e processos histórico-sociais. Todas as letras, v. 13, p. 114-129, 2011. Disponível em: <http://editorarevistas.mackenzie.br/index.php/tl/article/ view/3734/2971>. Acesso em: 6 set. 2014.

BUTLER, J. Fundamentos contingentes: o feminismo e a questão do "pós-modernismo". In: Cadernos Pagu, n. 11, p. 11-42, 1998. Disponível em: <http://www.bibliotecadigital. unicamp.br/document/?code=51196>. Acesso em: 10 jan. 2016 .

CASTRO, Y. P. Falares africanos na Babia: um vocabulário afro-brasileiro. 2. ed. Rio de Janeiro: TopBooks, 2005.

. A língua brasileira é culturalmente negra: entrevista. 01 jan. 2015. São Paulo:

Revista de História. Entrevista concedida a Marcello Scarrone.

CAVARERO, A. Vozes plurais: filosofia da expressão vocal. Belo Horizonte: UFMG, 2011.

DERRIDA, J. Gramatologia. São Paulo: Perspectiva. 1973.

DIAGNE, M. Lógica do escrito, lógica do oral: conflito no centro do arquivo. In: A produção do saber na África contemporânea. HOUNTONDJI, P. J. (Org.). Luanda: Edições Pedago, 2012.

DOLAR, M. Una voz y nada más. Buenos Aires: Manantial, 2007. 227 p.

ERRINGTON, J. Colonial linguistics. Annual Review of Anthropology, v. 30, p. 19-39, 2001. 
FARDON, R.; FURNISS, G. Frountiers and boundaries: african languages as political environment. In: FARDON, R.; FURNISS, G. African languages, development and the state. New York: Routledge, 1994.

FINNEGAN, R. O que vem primeiro: o texto, a música ou a performance? In: MATOS, C.N.; TRAVASSOS, E.; MEDEIROS, F.T. (Org.). Palavra Cantada - ensaios sobre poesia, música e voz. Rio de Janeiro: 7Letras, 2008.

FOUCAULT, M. A história da sexualidade: A vontade de saber. 13. ed. Tradução de Maria Thereza da Costa Albuquerque e Gilhon Albuquerque. Rio de Janeiro: Graal, 1999.

O nascimento da clínica. Tradução de Roberto Machado. Rio de Janeiro: Forense Universitária, 1977.

GASPAR, E. D. (Org.). Cantigas de umbanda e candomblé: pontos cantados e riscados de orixás, caboclos, pretos velhos e outras entidades. Rio de Janeiro: Pallas, 2011.

GLISSANT, É. Introdução a uma poética da diversidade. Juiz de Fora: UFJF, 2005.

MAKONI, S. B.; MEINHOF, U. Linguística aplicada na África: desconstruindo a noção de língua. In: LOPES, M. (Org.). Por uma linguística aplicada indisciplinar. São Paulo: Parábola Editorial, 2006. p. 191-210.

MAKONI, S. B.; SEVERO, C. G. Discourses of language in colonial and postcolonial Brazil. In: Language and communication, v. 34, p. 95-104, 2013. Disponível em: <http:// www.sciencedirect.com/science/article/pii/S0271530913000682>. Acesso em: 27 ago. 2014.

Lusitanization and bakhtinian perspectives on the role of Portuguese in Angola and East Timor. Journal of Multilingual and Multicultural Development, v. 36, p. 151$162,2015$.

MARCUSCHI, A. Da fala para a escrita: atividades de retextualização. São Paulo: Cortez, 2008.

MARIANI, B. Colonização linguística. Campinas: Pontes, 2004.

MARTINS, L. Performances da oralitura: corpo, lugar da memória. Letras (UFSM), n. 26, p. 63-81, jun. 2003.

MIGNOLO, W. Desobediência epistêmica: a opção descolonial e o significado de identidade em política. Cadernos de Letras da UFF - Dossiê: Literatura, Lingua e Identidade, n. 34, p. 287-324, 2008.

MUDIMBE, V. Y. A invenção de África: gnose, filosofia e a ordem do conhecimento. Mangualde: Edições Pedago; Luanda: Edições Mulemba, 2013. 
OLSEN, D. Oral discourse in a world of literacy. Research in the teaching of english, v. 41, n. 2, p. 136-143, 2006.

ONG, W. Orality and literacy. New York: Routledge, 2002.

PRANDI, R. Mitologia dos Orixás. São Paulo: Companhia das Letras, 2014.

QUEIROZ, S. Remanescentes culturais africanos no Brasil. Aletria, v. 9, 2002. Disponível em: <http://www.periodicos.letras.ufmg.br/index.php/aletria/article/view/1297>. Acesso em: 15 jan. 2015.

QUIJANO, A. Colonialidad del poder, eurocentrismo y América Latina. In: A colonialidade do saber: eurocentrismo e ciências sociais - perspectivas latino-americanas. Buenos Aires: CLACSO, 2005. Disponível em: <http://biblioteca.clacso.edu.ar/gsdl/collect/clacso/index/assoc/D1207.dir/12_Quijano.pdf>. Acesso em: 03 mar. 2015.

RAJAGOPALAN, K. Por uma linguística crítica: linguagem, identidade e a questão ética. São Paulo: Parábola Editorial, 2013.

SAUSSURE, F. Curso de linguística geral. São Paulo: Cultrix, 2006.

SEVERO, C.; MAKONI, S. Políticas linguísticas Brasil-África: por uma perspectiva crítica. Florianópolis: Insular, 2015.

TRAVASSOS, E. Um objeto fugidio: voz e "musicologias". In: MATOS, C. N.; TRAVASSOS, E.; MEDEIROS, F. T. (Org.). Palavra Cantada: ensaios sobre poesia, música e voz. Rio de Janeiro: 7Letras, 2008.

ZUMTHOR, P. Escritura e Nomadismo. Tradução de Jerusa Pires Ferreira e Sonia Queiroz. Cotia: Ateliê Editorial, 2005. 